TOTAL HIP REPLACEMENT: RESULTS OF A POSTAL SURVEY OF CURRENT PRACTICE ON THE CEMENT FIXATION OF THE ACETABULAR CUP IN THE UK

\title{
Authors:
}

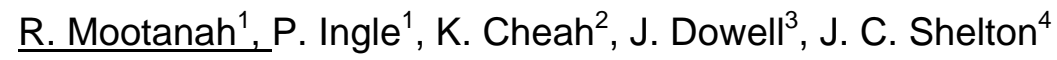

Institutions:

1. Bioengineering Research Group - DaCS

Anglia Polytechnic University

2. Orthopaedic Department

Springfield Hospital

3. Mid-Essex Hospital Services

Orthopaedic Department

Broomfield Hospital

4. Department of Engineering and IRC in Biomedical Materials

Queen Mary University of London

\section{Source of grant:}

The Chelmsford Medical Education and Research Trust

\section{Corresponding author:}

Dr Rajshree Mootanah

Bioengineering Research Group

Design and Engineering, DaCS

Bishop Hall Lane

Chelmsford

Essex

CM1 1SQ

United Kingdom

Tel: (44) 1245493131 ext 3316

Fax: (44) 1245252646

E-mail: r.mootanah@apu.ac.uk 


\section{Abstract}

Previous finite element studies and laboratory investigations on reconstructed acetabulum joints show that long-term fixation of the acetabular cup in total hip replacements (THRs) is influenced by surgical fixation techniques. The aim of this study is to determine and understand the reasons of current practice in the cement fixation of the acetabular cup in THRs in the UK. Following a pilot study, a postal survey was carried out among 1350 orthopaedic consultants. Response rate was $40 \%$ and data obtained from the returned questionnaires provided information about the current practice of 431 consultants with an average of 16.5 years of experience and who perform an average of 55 cemented THR operations annually. The survey showed wide variations in the fixation methods of the acetabular component. $95 \%$ of the respondents use cement to fix the acetabular cup, $46 \%$ maintain the subchondral bone and $63 \%$ use a flanged acetabular cup. The numbers of anchorage holes drilled vary from zero to thirty-six and drill diameters vary from 2 to $15 \mathrm{~mm}$. Anchorage hole depths vary from 3 to $20 \mathrm{~mm}$. Given the variability of surgical fixation methods, further studies need to be carried out to determine how fixation techniques could be improved to increase the longevity of the acetabular component in THRs. Further investigations could lead to a better understanding of the factors that contribute to the stability of THRs.

Keywords: Total hip replacement, current practice, acetabular cup fixation

\section{Introduction}

THR provides quick relief of pain, rapid mobilisation and independent living for numerous people who would otherwise be disabled. Every year, nearly 50,000 THRs are performed in the UK and over 120,000 in the United States [1]. The demand for THR is likely to increase with the ageing population in the UK. Failure of the acetabular implant fixation in primary THRs increases exponentially ten years following surgery and occurs mostly at the bone cement interface [2]. The average cost of cemented total hip replacement in the NHS Trusts 
is over $£ 4,000$ and revision surgery can be two to three times more expensive THR [3]. THR represents a substantial resource cost of about $£ 140$ million to the National Health Service (NHS) every year. Moreover, because of the increasing demand for hip replacement, especially amongst the young, the longevity of the acetabular implant needs to be improved.

During cement fixation of the acetabular cup, anchorage holes are drilled in the acetabulum in order to increase the torsional and fatigue resistance of cement bonding at the bonecement interface. Previous finite element studies and laboratory investigations show that the stability of the acetabular cup is influenced by surgical fixation techniques [4-9]. However, there seems to be wide variations in the preparation of the acetabulum prior to cementation. These include the number, geometry and distribution of anchorage holes and removal or preservation of the subchondral bone. In order to understand current practice, a postal survey was carried out amongst orthopaedic consultants in the UK. The data obtained from the returned questionnaires provides information about the current practice of 431 orhtopaedic consultants who have an average of 16.5 years of experience and perform an average of 55 cemented hip operations per year.

This study investigated current practice in the cement fixation of the acetabular cup in total hip replacement. The data received is not to be interpreted as best practice. However, this data, together with results obtained from finite element studies and laboratory investigations may lead to a better understanding of the factors that contribute to the stability of total hip replacements.

\section{Method}

A survey questionnaire was designed with closed questions in order to collect information about the following: 
1. The use of cement for fixing the acetabular cup. We excluded the types of cement used, for example, low viscosity cement, and the types of cement preparation, for example, second generation and vacuum mixing.

2. The number of cemented total hip replacement operations performed each year.

3. Whether the subchondral bone is maintained or removed when reaming the acetabulum.

4. The number of anchorage holes drilled, whether this differs from patient to patient, the distribution and location of the anchorage holes. Information was obtained by requesting the participants to mark on a diagram of the acetabulum provided where they normally drill anchorage holes in the acetabulum.

5. The diameter and depth of holes drilled.

6. The angle of inclination at which the holes are drilled.

7. Other ways of producing anchorage holes.

8. The most common mode of acetabular implant failure observed during revision surgery.

9. The use of flanged acetabular cup.

10. The number of years for which respondents have been practising. This information could give an indication of how methods of cemented fixation of the acetabular cup have changed with length of practice.

A pilot survey was carried out amongst 12 consultants in order to validate the questions and then the questionnaire was redesigned in light of their comments. The questionnaire was restructured into 24 mixed opened and closed questions [10]. These were then sent to 1350 orthopaedic consultants who were Fellows of the British Orthopaedic Association. There were in total 534 respondents, making a response rate $40 \%$. Amongst those, 80 had retired and did not fill the questionnaire so the number of questionnaires considered for this survey was 454. The responses were kept anonymous.

The answers received for the open questions were categorised into groups and the data obtained for every question were entered into 'Statistical Products and Service Solutions' (SPSS) software for statistical analyses. 


\section{Results}

Nearly $90 \%$ of the consultants who participated in the survey had between 5 and 25 years of experience, with $27.5 \%$ at $6-10$ years, $20.8 \%$ at $11-15$ years and $23.2 \%$ at $16-20$ years. Less than $3 \%$ responded with less than 5 years experience.

$5.1 \%$ of the respondents do not use cement to fix the acetabular cup. $90.7 \%$ use cement and $4.2 \%$ use both methods. Most of the questions were related to the cemented fixation of the acetabular cup and were based on the responses obtained from the 431 practitioners who use cement during the operation. In most cases the total percentage exceeds $100 \%$ because some respondents gave more than one reason for the method they use.

\section{Maintenance or removal of the subchondral bone}

During the preparation of the acetabular socket, 198 (46\%) of the consultants maintain the subchondral bone, $174(41 \%)$ remove it while 54 (13\%) partially remove it. Figure 1 illustrates the reasons why orthopaedic consultants choose each different method of preparation of the acetabulum floor. Whichever the method of fixation, the main reason remains for better fixation. This includes cement interdigitation, for better mechanical support and to preserve strength of underlying bone and anatomy.

\section{Anchorage holes}

$96.3 \%$ of the respondents drill or impact anchorage holes when fixing the acetabular implant. The presence of the subchondral bone leaves the consultants with a need to drill anchorage holes (75\%), whilst removing it reduced the need for drilling holes (19\%). Nearly $25 \%$ of the respondents use a curette and $10 \%$ use a gouge as alternative means of creating anchorage holes. $65 \%$ of the respondents drill anchorage holes. 


\section{Number of anchorage holes drilled}

Of the 431 respondents who produce anchorage holes, $23 \%$ drill 0 to 2 anchorage holes, $24 \%$ drill 3 to 4 anchorage holes and $23 \%$ drill 6 to 8 anchorage holes. The remaining produce 9 to 36 anchorage holes.

\section{Distribution of anchorage holes}

The acetabulum was divided into 9 regions, as shown in figure 2. Table I shows that more holes are drilled in the superior part of the acetabulum and in the ischium. Very few anchorage holes are drilled in the centre of the acetabulum and in the notch area. Of the 414 consultants who drill anchorage holes, 61\% select some particular locations for better fixation. The reasons include stabilisation of the bone cement interface, rotational stability through macro-interlock and to obtain increased cancellous surface for micro-interlock in the weight-bearing area. $33 \%$ selected the region for safety reasons (where there is adequate depth to avoid danger of penetrating vessels or the pelvis) and $14 \%$ drilled in particular locations to achieve the desired size and number of anchorage holes.

\section{Variation of number of anchorage holes}

$72 \%$ of the consultants who took part in this survey drill varying numbers of anchorage holes on different patients (Some examples are shown in Figure 3.). $62 \%$ of these respondents do so depending on the size of the acetabulum and $41 \%$ do so depending on bone quality.

\section{Depth and diameter of anchorage holes}

Figure 4 shows the percentage respondents drilling varying depths and diameters of anchorage holes. It is interesting to note that the most common depths of anchorage holes drilled are in the two extremities, between 3 and $6 \mathrm{~mm}$ and over $10 \mathrm{~mm}$ deep.

More than two thirds of the respondents drill anchorage holes between 3 and $6 \mathrm{~mm}$ diameter and nearly one fifth drill anchorage holes with diameter of $10 \mathrm{~mm}$ or larger. This trend is 
similar to the response obtained for the depth of anchorage holes and reflects the argument that depth does not need to be greater than diameter for increased stability.

$29 \%$ of the respondents drill anchorage holes to a particular depth because there is a stop on the drill bit or because of the standard drill bit provided in theatre. $28 \%$ of the consultants did not give a reason for drilling anchorage holes to the preferred depth or thought that the depth seemed sensible, was easy to drill or they were used to it. $24 \%$ drilled anchorage holes to a particular depth for better fixation (improved rotational stability, cement penetration and interdigitation), $15 \%$ did so for safety reasons (not to go through the inner cortex, the amount of bone stock available) and 14\% believe that increasing depth does not add strength.

Of the 414 respondents who drill anchorage holes, $30 \%$ use drill bit of a particular diameter to obtain adequate size for cement to enter, to introduce a curette and to wash the holes. $28 \%$ drill holes of a particular diameter because of the standard drill bit provided in theatre, $27 \%$ gave no reason for their choices, $13 \%$ want to maintain bone stock and strength, $11 \%$ do so to obtain better stability and safety (to obtain better rotational stability and fixation, or limit depth, or increase the surface area of the holes, or obtain anchorage holes of same size of diameter and depth) and 6\% use a particular size of drill bit, based on training, experience and literature.

$19 \%$ of the respondents drill different sizes of anchorage holes in a patient for different reasons. $37 \%$ of the 78 consultants who do so want to obtain fewer but larger holes the ilium, ischium and pubis and many small ones in the periphery of the acetabulum. $32 \%$ do so to improve fixation, $19 \%$ report that their choices depend on patients' bone quality, $12 \%$ depending on size of cup, $9 \%$ gave no reason for their choices and $8 \%$ do so to preserve the subchondral bone. 


\section{Angles at which Consultants attempt to drill anchorage holes}

$62 \%$ of the attempt to drill the anchorage holes at a particular angle and the overwhelming majority (98\%) of these consultants aim at $90^{\circ} .41 \%$ of these consultants aim to obtain better load distribution, fixation and stability (to obtain anti-rotational lugs, to avoid shearing at the bone-cement interface, to lower risks of cement plugs breaking, to obtain maximum contact at bone cement interface or for even pressurisation). $34 \%$ do so by intuition or because they feel this was more appropriate or gave no reason for their choice. $14 \%$ believe that this drilling technique would improve access for cement, $12 \%$ choose to drill at a particular angle for ease or to prevent the drill from slipping and $6 \%$ do so for safety reasons (to avoid penetration, to prevent side bone from collapsing, not to weaken the subchondral bone or for minimum bone loss).

\section{Use of flanged acetabular cups}

$63 \%$ of the consultants use flanged acetabular cups. $91 \%$ do so in order to retain cement under pressure. $22 \%$ do so to obtain better fixation or to obtain better a cement mantle or surface area contact. $4 \%$ believe that flanged cup reduces wear at the bone-cement interface.

\section{Nature of failure at revision}

Failure at the bone-cement interface, including fracture of the cement mantle and cement pegs, was reported to be the most common cause of failure of THRs (58\%) and loosening or cup instability was reported by $56 \%$ of the consultants. $20 \%$ reported that failure is caused by implant failure, wear, fracture or deformation of cup and $16 \%$ associate implant failure to osteolysis, bone resorption or presence of fibrous membrane. It seems that the most common causes for revision surgery are related with fixation methods.

\section{Correlations between number of years of practice and current practice}


Some correlations were observed between the consultants' experience in terms of length of practice and current practice. More than $95 \%$ of the younger consultants with up to 10 years of experience perform only cemented fixation of the acetabular cup compared to $85 \%$ of the consultants with 21-25 years of experience. There is almost twice the percentage of consultants with over 15 years of experience who partially remove the subchondral bone compared to those with up to 15 years of experience. There is a tendency among the younger generation of consultants to produce higher numbers of anchorage holes with smaller diameters and depths.

\section{Discussion}

The data shows wide variations in current practice regarding the use of cement, the removal of the subchondral bone, the number, geometry, locations and distribution of anchorage holes drilled and the use of flanged acetabular cups.

In the early 1980's high rates of late loosening of cemented acetabular cup were reported $[11,12]$. This was soon followed by the emergence of theoretical advantages that introducing cementless acetabular components could reduce wear-debris at the bone-cement interface. In the 1980's non-cemented fixation of the acetabular component started to become popular. These factors might have influenced consultants with over fifteen years of practical experience to perform non-cemented fixation of the acetabular cup and to partially remove the subchondral bone. However, more recent clinical and longer follow-up studies show that results of non-cemented fixation of the acetabular component are inferior to those reported in short-term survival studies [13-15]. The potential disadvantages when implanted in older patients with osteoporosis [14] have not yet reached the standard set by cemented fixation [15]. This could have influenced younger consultants to perform cemented fixations.

The first generation of cementing techniques [16], whereby three large anchorage holes were recommended, may have influenced consultants with more than fifteen years of experience 
to drill fewer, larger and deeper anchorage holes, irrespective of patient acetabular size. The second generation of cementing techniques [15], whereby a large number of smaller anchorage holes are produced [17], could have influenced the younger generation of surgeons. Consultants with less than 15 years of experience drill a larger number of smaller and shallower anchorage holes and, as a result, tend to drill varying numbers of anchorage holes on different patients.

A variety of reasons were given for the different methods of fixation of the acetabular cup. Fixation techniques have been reported to have profound effects on the torque resistance at the bone-cement interface [4-9,15-25]. This is in line with response obtained from the survey, that is, failure at the bone cement interface, including failure of the cement mantle and cement pegs, was the primary cause for revision surgery. However, few studies give enough information on the fixation techniques used, such as whether the acetabulum was prepared to restore anatomical position and to preserve as much subchondral bone support as possible [26] or reamed until bleeding cancellous bone is exposed [17]. Very few studies mention whether anchorage holes are drilled in the acetabulum at all [26]. Cornell and Ranawat [17] are among the very few investigators to give elaborate information on the number and size of anchorage holes drilled in their study.

\section{Conclusion}

This study has brought out the importance of fixation techniques of the acetabular component in THR and yet the wide variations in current surgical practice. Further investigations could lead to a better understanding of the factors that contribute to the longterm stability of total hip replacements. The size of the acetabulum and quality of bone varies from patient to patient. Therefore, the optimum geometry and distribution of anchorage holes may need to vary to accomodate these anatomical differences. Further studies on the ratio of diameter to depth of anchorage holes and the ratio of size of the acetabulum to diameter of 
anchorage holes could assist in identifying the ideal method of preparation of the acetabulum.

Comparison of survivorship studies of different implants could be compromised if fixation techniques are not taken into account. These uncertainties make it difficult to combine different studies with confidence. The degree to which factors affecting the fixation of implants are controlled varies from investigator to investigator. If the fixation techniques are taken into consideration when compiling results from follow-up studies, more accurate results will be obtained, leading to greater agreement among authors.

\section{Acknowledgements}

The authors wish to thank the Chelmsford Medical Education and Research Trust and all the orthopaedic consultants who took part in this survey.

\section{References}

1. National Institutes of Health. Total Hip Replacement. In: Consensus Development Conference Statement, online September 12-14 1994;12(No.5): 1-31.

2. Morscher E. Current status in acetabular fixation in primary hip arthroplasty. Clin Orthop 1992; 274: 172-187.

3. National Audit Office. Hip replacements: Getting it right first time. Report by Comptroller and Audit Comptroller, 2000.

4. Mootanah R, New A, Pearmain D, Ingle P, Dowell J, Cheah K. Cemented fixation of the acetabular cup in total hip replacement: improving the distribution of anchorage holes by finite element method. In: Middleton J, Jones ML, Shrive NG, Pande GN, eds. Computer Methods in Biomechanics and Biomedical Engineering. Amsterdam: Gordon and Breach Science Publishers 2001; 3; 33-38.

5. Mootanah R, Ingle P, Dowell J, Cheah K Shelton JC. Fixation of the acetabular cup in cemented total hip replacement: improving the anchorage hole profile using finite element method, Technol Health Care 2000; 8(No. 6): 343-355. 
6. Oh I. A comprehensive analysis of the factors affecting acetabular cup fixation and design in total hip replacement arthroplasty: A series of experiment and clinical studies. Proceedings of the Open Scientific Meeting 1983; 11: 120 -177.

7. Mootanah R, Ingle $\mathrm{P}$, Cheah $\mathrm{K}$, Dowell J, Shelton JC. Using finite element methods to investigate the effect of removing the subchondral bone during the cemented fixation of the acetabular cup in total hip replacement. In: Proceedings of the tenth International Congress on Biological and Medical Engineering. Singapore: International Society of Biological and Medical Engineering proceedings 2000; 10: 171-172

8. Mburu G, Hutchinson JD, Aspden RM. Optimizing the configuration of cement keyholes for acetabular fixation in total hip replacement using Taguchi experimental design. Proc Inst Mech Eng [H] 1999; 213: 485-492.

9. Mootanah R, Ingle $\mathrm{P}$, Jarrett $\mathrm{P}$, Cheah $\mathrm{K}$, Dowell J, Shelton JC. Improving the distribution of anchorage holes during cemented fixation of the acetabular cup in total hip replacement: validation of finite element models. In: Kenny L, Mickelborough J, Nester C, Rithalia S, eds. Proceedings of the first conference of biomechanics of the lower limb in health, disease and rehabilitation. Salford: Society of biomechanics of the lower limb in health, disease and rehabilitation 2001; 1: 146-147.

10. Armitage P, Berry G. Statistical methods in medical research. Oxford: Blackwell Scientific Publications, 1994:1-39.

11. De Lee JG, Charnley J. Radiological demarcation of cemented sockets in hip replacement. Clin Orthop 1976; 121: 20-32.

12. Wroblewski BM. 15-21 year results of the Charnley low friction arthroplasty. Clin Orthop 1986; 211: 30-35.

13. Havelin LI, Espehaug B, Vollset SE, Engesaeter LB. Early failures among 14,009 cemented and 1,326 uncemented prostheses for primary coxarthrosis. The Norwegian Arthroplasty Register 1987-1992. Acta Orthop Scand 1994; 65:1-6.

14. Ranawat CS, Deshmukh RG, Peters LE, Umlas ME. Prediction of the long-term durability of all-polyethylene cemented sockets. Clin Orthop 1995; 317: 89-105. 
15. Malchau $\mathrm{H}$, Herberts $\mathrm{P}$. Prognosis of total hip replacement - Surgical and cementing technique in THR: A revision-risk study of 148,359 primary operations. In: Proceedings of the sixty fifth Annual Meeting of the American Academy of Orthopaedics Surgeons. New Orleans: American Academy of Orthopaedics Surgeons 1998; 65.

16. Charnley J. Low friction arthroplasty of the hip. Theory and practice. Berlin: Springer, 1979.

17. Cornell CN, Ranawat CS. The impact of modern cementing techniques on acetabular fixation in cemented total hip replacement. J Arthroplasty 1986; 1(3): 197-202.

18. Volz RG, Wilson RJ. Factors affecting the mechanical stability of the cemented acetabular component in total hip replacement. J Bone Joint Surg [A] 1977; 59(4): 501504.

19. Jacob HA, Huggler A, Dietschi C, Schreiber A. The mechanical function of subchondral bone as experimentally determined on the acetabulum of the human pelvis. J Biomech 1976; 9: 625-627.

20. Eftekhar NS, Pawluk RJ. Role of surgical preparation in acetabular cup fixation. In: The Hip, Proceedings of the Eighth Open Scientific Meeting of the Hip Society. The Hip Society 1980; 8: 308-328.

21. Ranawat CS, Rawlins BA, Harju VT. Effect of modern cement technique on acetabular fixation total hip arthroplasty - a retrospective study in matched pairs. Orthop Clin North Am 1988; 19(3): 599-603.

22. Kobayashi S, Terayama K. Radiology of low-friction arthroplasty of the hip: a comparison of socket fixation techniques. J Bone Joint Surg [Br] 1990; 72-B: 439-443.

23. Majkowski RS, Miles AW, Bannister GC, Perkins J, Taylor GJS. Bone surface preparation in cemented joint replacement. J Bone Joint Surg [Br] 1993; 75-B(3): 459463.

24. Ziegler BS, Lachiewicz PF. Survivorship analysis of cemented total hip arthroplasty acetabular components implanted with second-generation techniques. J Arthroplasty 1996; 11(6): 750-756. 
25. Thanner J. The acetabular component in total hip arthroplasty. Evaluation of different fixation principle (Abstract). Acta Orthop Scand suppl 1999; 286: 1-41.

26. Wixson RL, Stulberg SD, Mehlhoff M. Total hip replacement with cemented, uncemented, and hybrid prostheses - a comparison of clinical and radiographic results at two to four years. J Bone Joint Surg [Am] 1991; 73-A(2): 257-270. 


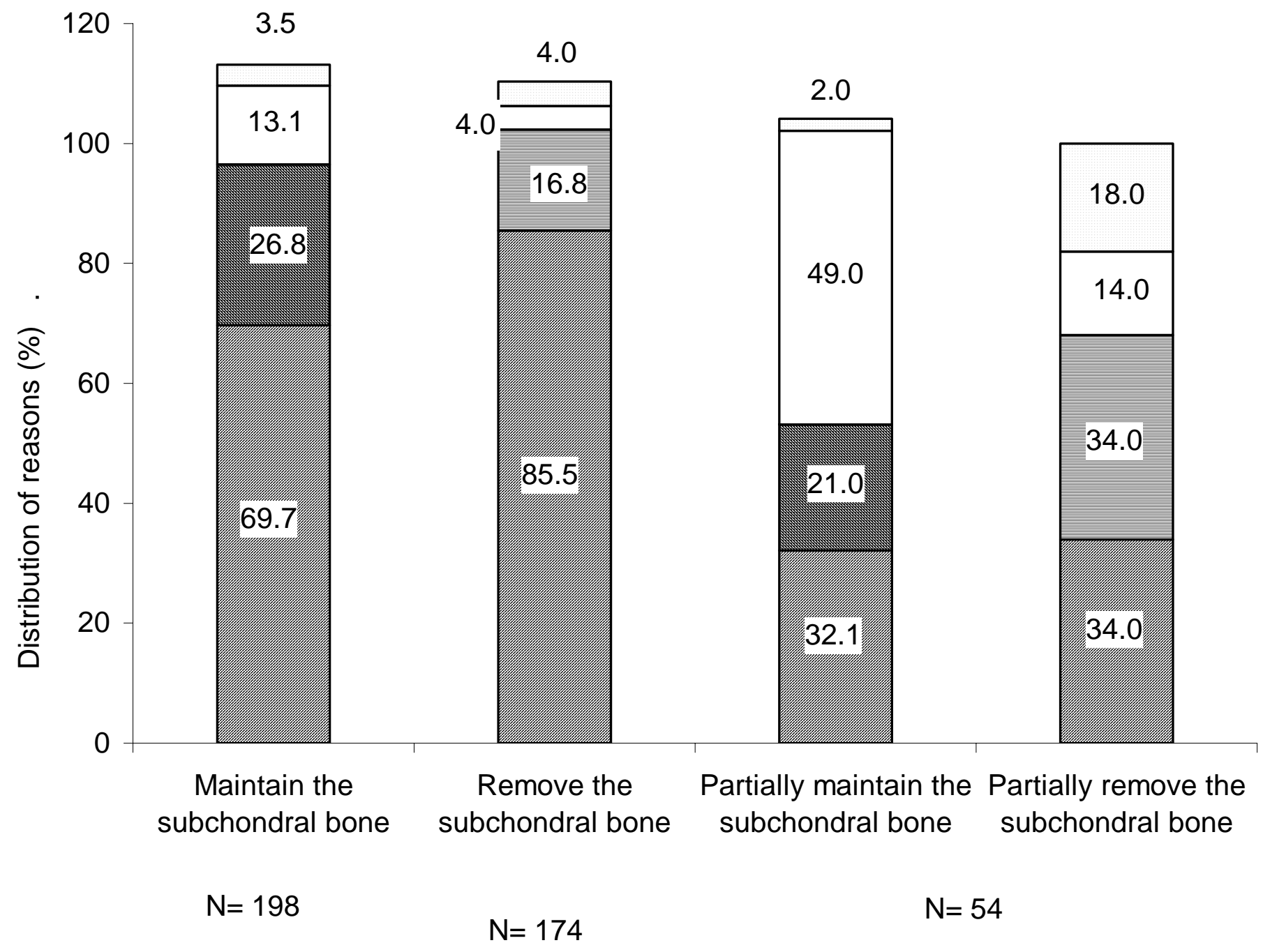

Preparation of the acetabulum floor

$\square$ For better fixation $\square$ To position the cup $\square$ To preserve bone stock $\square$ None $\square$ Others

Fig. 1: Reasons removing or keeping the subchondral bone 
Table I: Distribution and mean number of

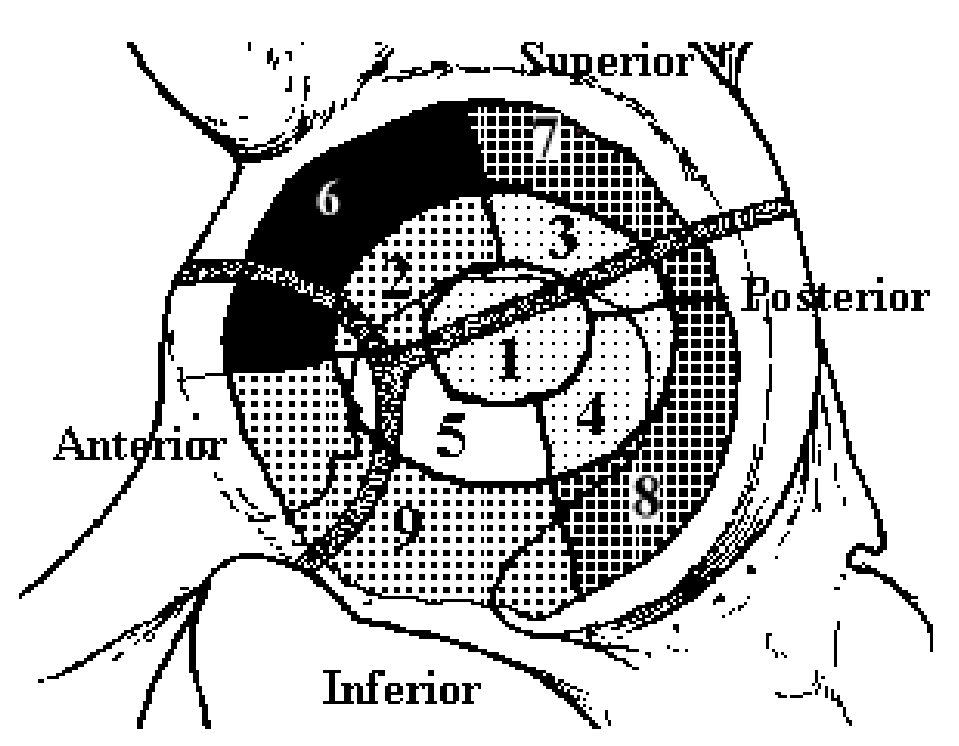

Fig. 2:Number of holes drilled in the

different regions of the left acetabulum anchoraqe holes drilled the acetabulum

\begin{tabular}{|c|c|c|}
\hline Location & $\begin{array}{l}\text { Total no. of } \\
\text { holes } \\
\text { drilled }\end{array}$ & $\begin{array}{l}\text { Mean no. of } \\
\text { holes } \\
\text { drilled }\end{array}$ \\
\hline & 798 & 1.801 \\
\hline 8曲曲曲曲 & 648 & 1.679 \\
\hline 7 典曲曲 & 598 & 1.549 \\
\hline 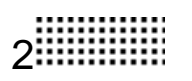 & 315 & 0.816 \\
\hline 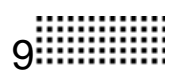 & 298 & 0.772 \\
\hline 3 3!ा & 282 & 0.731 \\
\hline 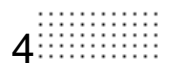 & 79 & 0.205 \\
\hline
\end{tabular}



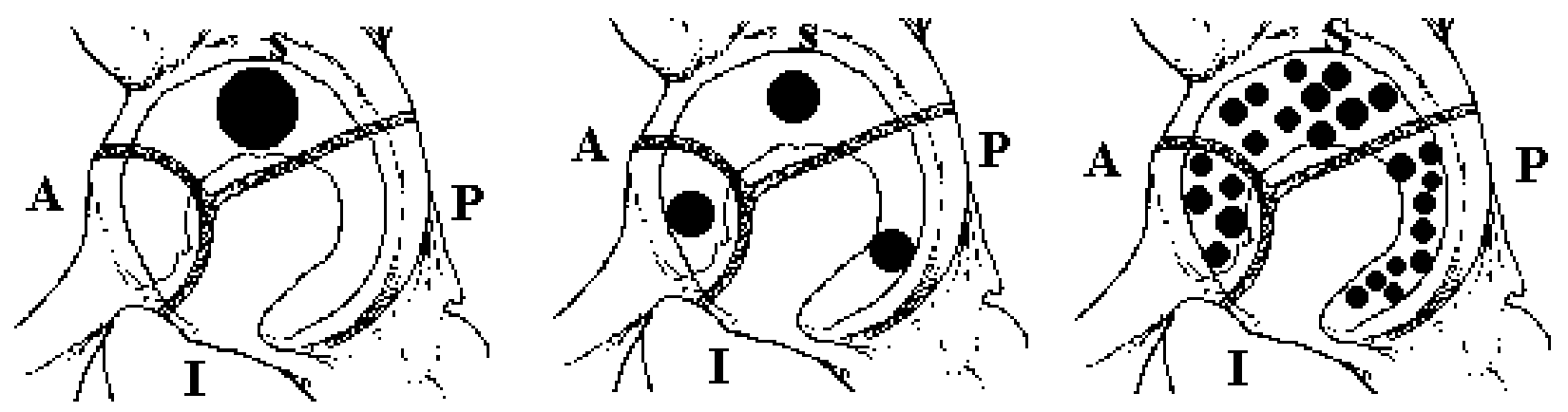

Fig. 3: Examples of distribution of anchorage holes in the left acetabulum in current practice 
$\mathrm{N}=414$

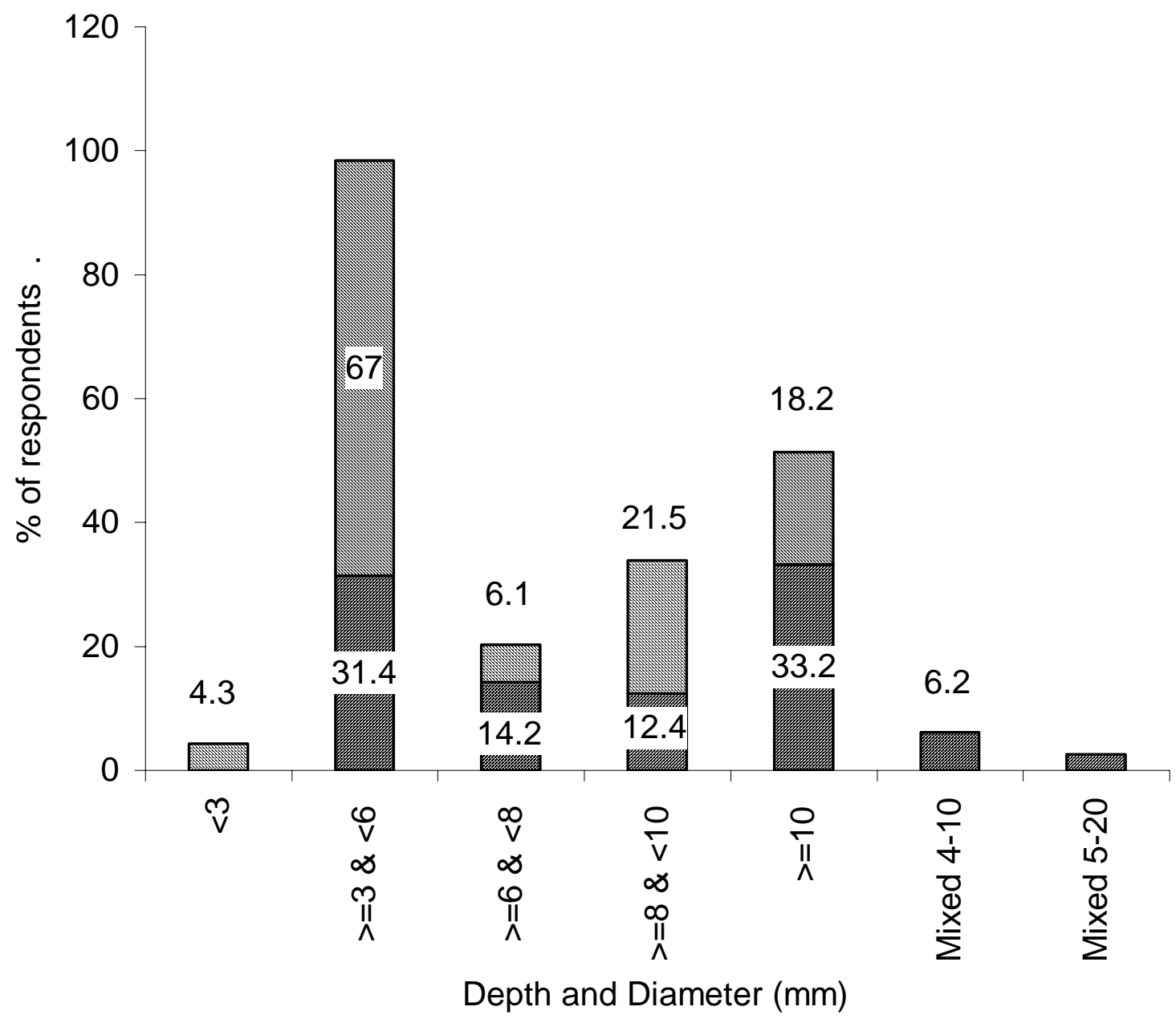

$\square$ Percentage of respondents using this diameter of drill bit $\square$ Percentage of respondents drilling anchorage holes of this depth

Fig. 4: Percentage of respondents drilling different depths and diameters of anchorage holes 